\title{
A rectifying ATP-regulated solute channel in the chloroplastic outer envelope from pea
}

\section{Bettina Bölter, Jürgen Soll ${ }^{1}$, Kerstin Hill², Roland Hemmler ${ }^{2}$ and Richard Wagner ${ }^{2}$}

\author{
Botanisches Institut, Universität Kiel, D-24118 Kiel and ${ }^{2}$ Fachbereich \\ Biologie/Chemie, Universität Osnabrück, D-49034 Osnabrück, \\ Germany \\ ${ }^{1}$ Corresponding author \\ e-mail: jsoll@bot.uni-kiel.de
}

B.Bölter and R.Hemmler contributed equally to this work

Phosphorylated carbohydrates are the main photoassimilated export products from chloroplasts that support the energy household and metabolism of the plant cell. Channels formed by the chloroplastic outer envelope protein OEP21 selectively facilitate the translocation of triosephosphate, 3-phosphoglycerate and phosphate, central intermediates in the source-sink relationship between the chloroplast and the cytosol. The anion selectivity and asymmetric transport properties of OEP21 are modulated by the ratio between ATP and triosephosphates, 3-phosphoglycerate and phosphate in the intermembrane space. Conditions that lead to export of triosephosphate from chloroplasts, i.e. photosynthesis, result in outward-rectifying OEP21 channels, while a high ATP to triosephosphate ratio, e.g. dark metabolism, leads to inward-rectifying OEP21 channels with a less pronounced anion selectivity. We conclude that solute exchange between plastids and cytosol can already be regulated at the level of the organellar outer membrane.

Keywords: ATP-triosephosphate regulation/chloroplast outer envelope/rectifying channel

\section{Introduction}

Members of the plastid organelle family carry out vital biosynthetic functions in every plant organ. Chloroplasts, chlorophyll-containing plastids, carry out photosynthesis, which converts atmospheric carbon dioxide to carbohydrates such as triosephosphate, starch and others. These and further biosynthetic pathway products and intermediates are exchanged continuously with the parent cell with the assistance of specific carrier proteins localized in the plastidic inner envelope (Flügge, 1998) and solute channels located in the chloroplastic outer envelope. While the inner envelope transport proteins, e.g. the triosephosphate/phosphate translocator (TPT), the dicarboxylic acid translocator or the hexose phosphate carrier, show a distinct substrate selectivity and specificity, it is not clear to what extent transport through the outer membrane channels is selective and regulated. Furthermore, it is not known how many different channels are present and are required in the outer membrane for plastid function. In mitochondria, a major solute channel with high conductance is represented by the voltage-dependent anion channel (VDAC) (Zoratti and Szabo, 1995; Kinnally et al., 1996). Although evidence exists that besides the porin-like VDAC channel additional high conductance channels could be present in the mitochondrial outer membrane, only a second VDAC-like protein has been identified (Benz, 1994; Szabo et al., 1995).

In Gram-negative bacteria, however, several different types of high conductance channels exist in the outer membrane (Nikaido, 1993). (i) So-called porins form water-filled pores that allow the downhill diffusion of solutes, provided that the size of the solutes does not exceed the exclusion limit ( 600 Da) of the channel pore (OmpF) (Schirmer et al., 1995). Modulation of these channels by ATP and other effectors has been reported for some of these porins, which casts doubt on the concept of a generally open diffusion pore (Rudel et al., 1996; Delcour, 1997; Iyer and Delcour, 1997; Samartzidou and Delcour, 1998, 1999). (ii) Porin-like channels, e.g. LamB from Escherichia coli, carry specific sites through which selective diffusion processes are facilitated (Keller et al., 1994; Schirmer et al., 1995). (iii) Ligand-gated pores, e.g. E.coli ferric enterobactin channels (FePA), provide energydependent uptake of nutrients into bacteria (Rutz et al., 1992; Jiang et al., 1997).

The ancestral relationship of mitochondria and plastids to Gram-negative bacteria (Margulis, 1970; Gray, 1993; Martin and Müller, 1998) suggests the presence of multiple channel proteins in the organellar outer membrane. In pea chloroplast outer membranes, three channel proteins have been identified and functionally characterized thus far. The preprotein-conducting channel with prokaryotic ancestors is formed by Toc75 (Hinnah et al., 1997; Bölter et al., 1998). The outer envelope protein of $16 \mathrm{kDa}$ (OEP16) forms a cation-selective highly conductive channel with a strong bias for amino acids and amines (Pohlmeyer et al., 1997). The channel characteristics of the third channel protein identified, OEP24 (Pohlmeyer et al., 1998), closely resemble those described for general diffusion pores (Benz, 1994). The gating properties, i.e. opening and closing of different channels, might be coordinated to reflect the metabolic needs of the communicating partners, e.g. chloroplast and cytosol. Little is known about how modulation of outer membrane channels is achieved in vivo, because a substantial membrane potential, as simulated in vitro by a voltage gate, is not likely to exist across the outer membranes in situ (for a review, see Klebba and Newton, 1998).

Here we describe the chloroplastic outer envelope protein from pea, OEP21. Reconstituted OEP21 protein forms a voltage-dependent, anion-selective channel. Of note is the asymmetric current-voltage relationship observed, as well as the tight modulation of the OEP21 
A
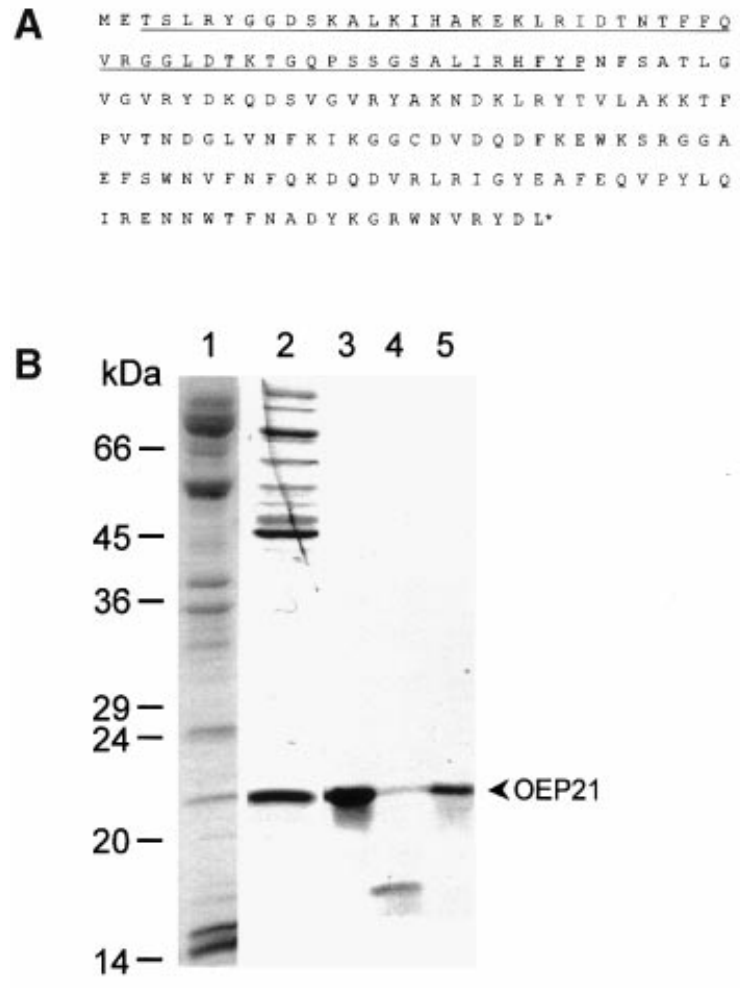

C

\begin{tabular}{|c|c|c|}
\hline \multicolumn{2}{|c|}{$\begin{array}{l}\text { chloroplast } \\
\text { membranes }\end{array}$} & total membranes \\
\hline PIS & & P21 \\
\hline $0^{4}$ & $0^{\varepsilon} \leqslant$ & $0^{\circ}$ \\
\hline
\end{tabular}

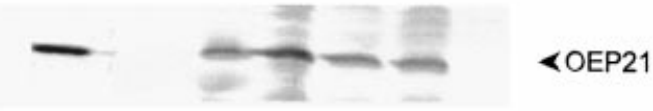

D
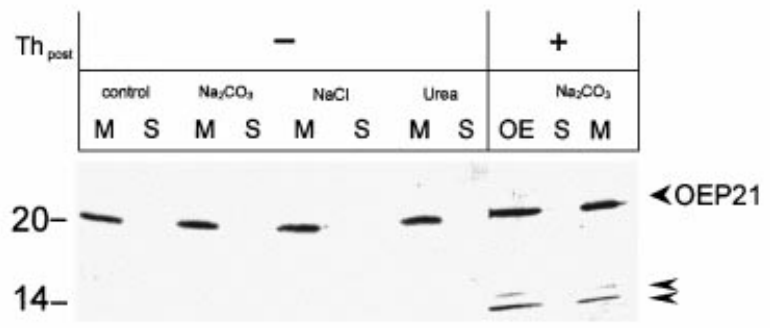

$\mathbf{E}$

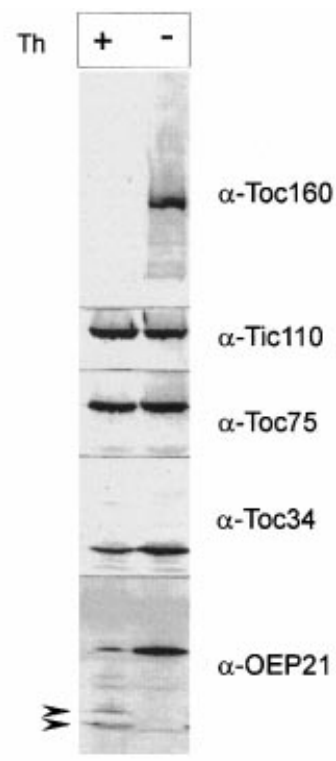

$\mathbf{F}$

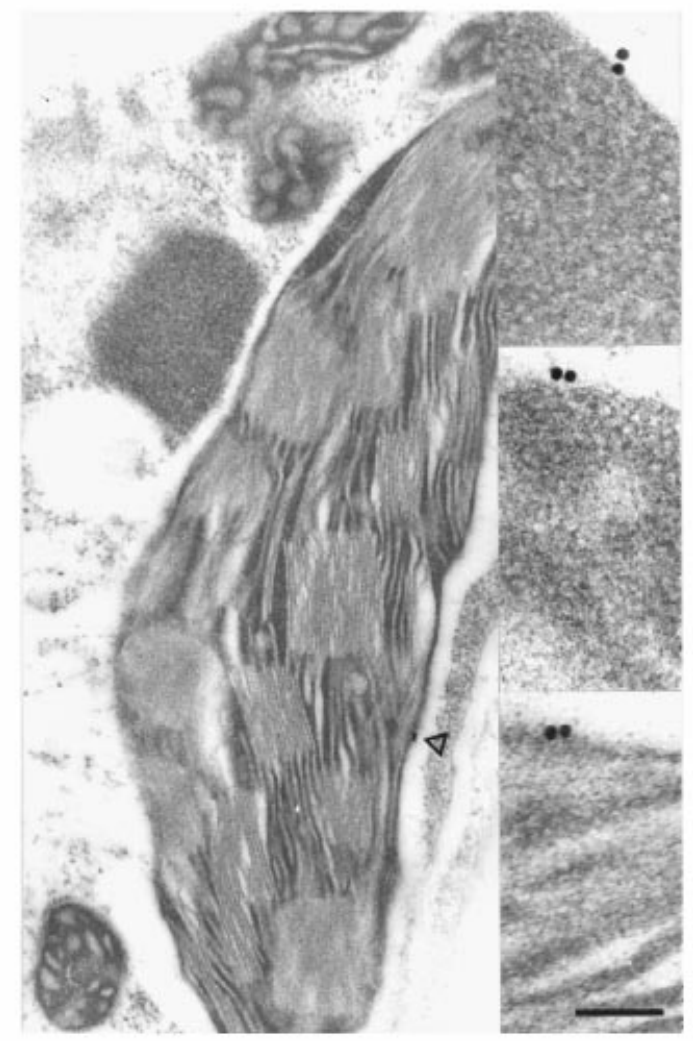

Fig. 1. Localization and distribution of OEP21 in pea. (A) Amino acid sequence as deduced from the clones peacOEP21 and peagOEP21. The N-terminal and internal amino acid sequences of OEP21 overlapped and are shown underlined. (B) Polypeptide composition of purified outer envelope membranes from pea (lane 1) and recombinant OEP21 (lanes 2-5). Recombinant OEP21 was recovered from insoluble inclusion bodies (lane 2) and purified by cation-exchange chromatography (lane 3). The eluate (lane 3) was fractionated further by size exclusion chromatography: lane 4 shows the last collected fraction that contains a low molecular weight protein; lane 5, OEP21 used for reconstitution. Numbers on the left indicate molecular weight standards in $\mathrm{kDa}$. (C) Immunoblot analysis of the presence of OEP21 in the outer envelope (OE), inner envelope (IE) and thylakoids (THY) from pea chloroplasts (10 $\mu \mathrm{g}$ of protein were loaded per lane), pea etioplasts, potato mitochondria or total membrane proteins from leaf, shoot or roots from pea (100 $\mu \mathrm{g}$ of protein loaded per lane). PIS, pre-immune serum; $\alpha$-OEP21, antiserum to OEP21. (D) Purified outer envelope membranes were either not treated (-) or treated (+) with the protease thermolysin (Th), extracted with $\mathrm{Na}_{2} \mathrm{CO}_{3}$ at $\mathrm{pH} 11,1 \mathrm{M} \mathrm{NaCl}$ or $4 \mathrm{M}$ urea and separated into a soluble (S) and insoluble membrane fraction (M). An immunoblot is shown using an OEP21 antiserum. The arrowheads indicate two proteolytic fragments of OEP21. (E) Purified intact pea chloroplasts (equivalent to $20 \mu \mathrm{g}$ of chlorophyll) were either not treated or treated with thermolysin. Total chloroplast membrane proteins were separated by SDS-PAGE and analysed for the presence of the different envelope proteins by immunoblot. (F) Immunogold labelling of ultra thin sections from pea leaves using the OEP21 antiserum. An overview is shown on the left. The right upper and middle panels represent independent labelling events of pea chloroplasts. The lower right panel is an enlargement of the overview indicated by the arrowhead. The scale bar represents $100 \mathrm{~nm}$ for the enlargements and $360 \mathrm{~nm}$ for the overview. 
A

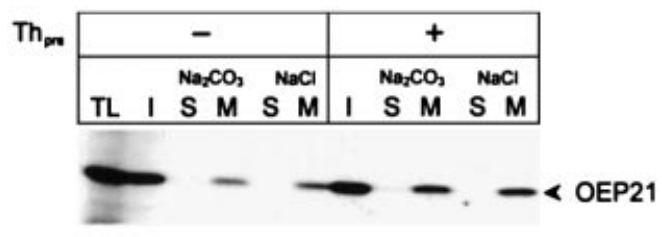

B
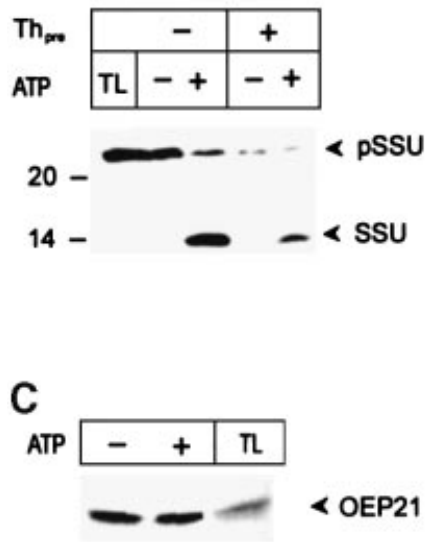

Fig. 2. Comparison of OEP21 and pSSU translocation into chloroplasts. Intact pea chloroplasts were incubated with ${ }^{35} \mathrm{~S}$-labelled OEP21 (A and C) or pSSU (B) translation product (TL) for 10 min at $25^{\circ} \mathrm{C}$. Chloroplasts were either not treated or treated with the protease thermolysin prior to the translocation reaction as indicated on the top of the figure. (A) Chloroplasts were recovered after import, washed and either not treated or treated with $\mathrm{Na}_{2} \mathrm{CO}_{3}$ at $\mathrm{pH} 11.5$ or $1 \mathrm{M} \mathrm{NaCl}$ as indicated and separated into soluble (S) and insoluble membrane (M) fractions. (B and C) Insertion of pSSU and OEP21 translation product in the absence $(-)$ or presence $(+)$ of $2 \mathrm{mM}$ ATP. TL, translation product, $10 \%$ of which was added to an import reaction. A fluorogram is shown.

channel activity by nucleotides and carbon intermediates of photosynthesis from the intermembrane space between the inner and outer plastid membrane. We conclude that the transport from and into plastids can already be regulated at the level of the outer membrane.

\section{Results}

Candidate outer envelope channel proteins should possess most of the characteristics of known channel proteins: (i) they are relatively abundant, because plastids are involved in many high 'throughput' biosynthetic pathways; (ii) many channel proteins are deeply embedded in the membrane and are resistant to proteolysis, e.g. the mitochondrial VDAC or the chloroplastidic OEP24, OEP16 and Toc75; and (iii) most channel proteins have a neutral or alkaline isoelectric point, e.g. VDAC, OMPF, OEP16 and OEP24. An unknown outer envelope polypeptide from pea with an apparent mol. wt of $21 \mathrm{kDa}$ was found to be abundant on SDS-PAGE (Figure 1B) and exhibited an alkaline isoelectric point. We therefore decided to analyse this protein in detail.

$\mathrm{N}$-terminal and internal peptide sequences with overlapping sequence information (Figure 1A) were obtained for the $21 \mathrm{kDa}$ protein after SDS-PAGE separation of purified outer envelope membranes. The $\mathrm{N}$-terminal protein sequence started with the amino acid glutamine, indicating that either the start methionine had been removed after translation, as detected frequently in a eukaryotic system (Walker and Bradshaw, 1999), or that the $21 \mathrm{kDa}$ polypeptide represents only a proteolytic fragment of a larger protein. Digoxygenin-labelled oligonucleotides were used to isolate the corresponding cDNA clone from a pea expression library. Both peptide sequences were found in the deduced open reading frame (ORF), thus demonstrating that the cDNA clone peacOEP21 codes for the $21 \mathrm{kDa}$ protein (Figure 1A). However, the deduced amino acid sequence of peacOEP21 lacked the start methionine and the first triplet coded for glutamic acid instead of glutamine in the protein sequence. A new homologous screening of the pea cDNA library did not result in a different isolate. We therefore decided to screen a pea genomic DNA library. The deduced ORF of the genomic clone peagOEP21 contained the missing start methionine, but had no further coding sequence information compared with peacOEP21. PeagOEP21 contained a stop codon $36 \mathrm{bp}$ upstream of the putative start ATG codon. From these data, we conclude that the outer envelope $21 \mathrm{kDa}$ polypeptide represents a full-length protein, from which methionine has been removed after translation. A protein of 177 amino acids, a calculated mol. wt of $20.8 \mathrm{kDa}$ and an isoelectric point of 9.6 can be deduced from the coding sequence (Figure 1A) which was deposited in the DDBJ/ EMBL/GenBank (accession No. AJ009987). We named the protein OEP21. Protein sequencing of OEP21 from two independent outer envelope preparations (Figure 1B) indicated glutamine as the N-terminal amino acid, while the ORFs of both peacOEP21 and peagOEP21 code for glutamic acid. It remains to be established whether this is due to a post-translational modification or to an in vitro artefact during the isolation of the OEP21 polypeptide. A database search revealed no significant homologies to other proteins, except to expressed sequence tags from rice and corn (accession Nos D49096 and AJ006545, respectively), indicating the presence of OEP21 in both monocotyledonous and dicotyledonous plants.

Sequence analysis reveals that OEP21 has an unusually high content of polar and charged amino acids (51\%) for a membrane protein. Indeed, a computer algorithm that is also able to predict membrane proteins, e.g. TopPredII (von Heijne, 1992), indicated that OEP21 is likely to be a soluble protein. To establish further its chloroplast origin, immunolocalization and protein translocation experiments were conducted. An antiserum raised against the recombinant protein recognized one protein in the chloroplastic outer envelope. Little or no cross-reaction occurred with inner envelopes or thylakoids and mitochondria (Figure 1C), respectively. OEP21 is present in chloroplasts, etioplasts and non-green plastids from roots, demonstrating its presence in different plastid types (Figure 1C). OEP21

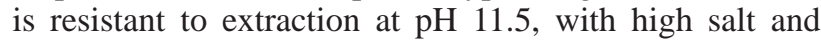
$4 \mathrm{M}$ urea, respectively, thus behaving like an integral membrane protein (Fujiki et al., 1982; Figure 1D). Treatment of right-side-out outer envelope vesicles with the protease thermolysin results in two distinct proteolytic fragments of 14 and $10 \mathrm{kDa}$ apparent mol. wt (Figure 1D). Both fragments are resistant to extraction at $\mathrm{pH}$ 11.5. When intact chloroplasts were treated with the protease thermolysin, the outer envelope proteins Toc160, Toc34 and OEP21 were proteolytically cleaved. The proteolytic fragments obtained from OEP21 in intact chloroplasts 

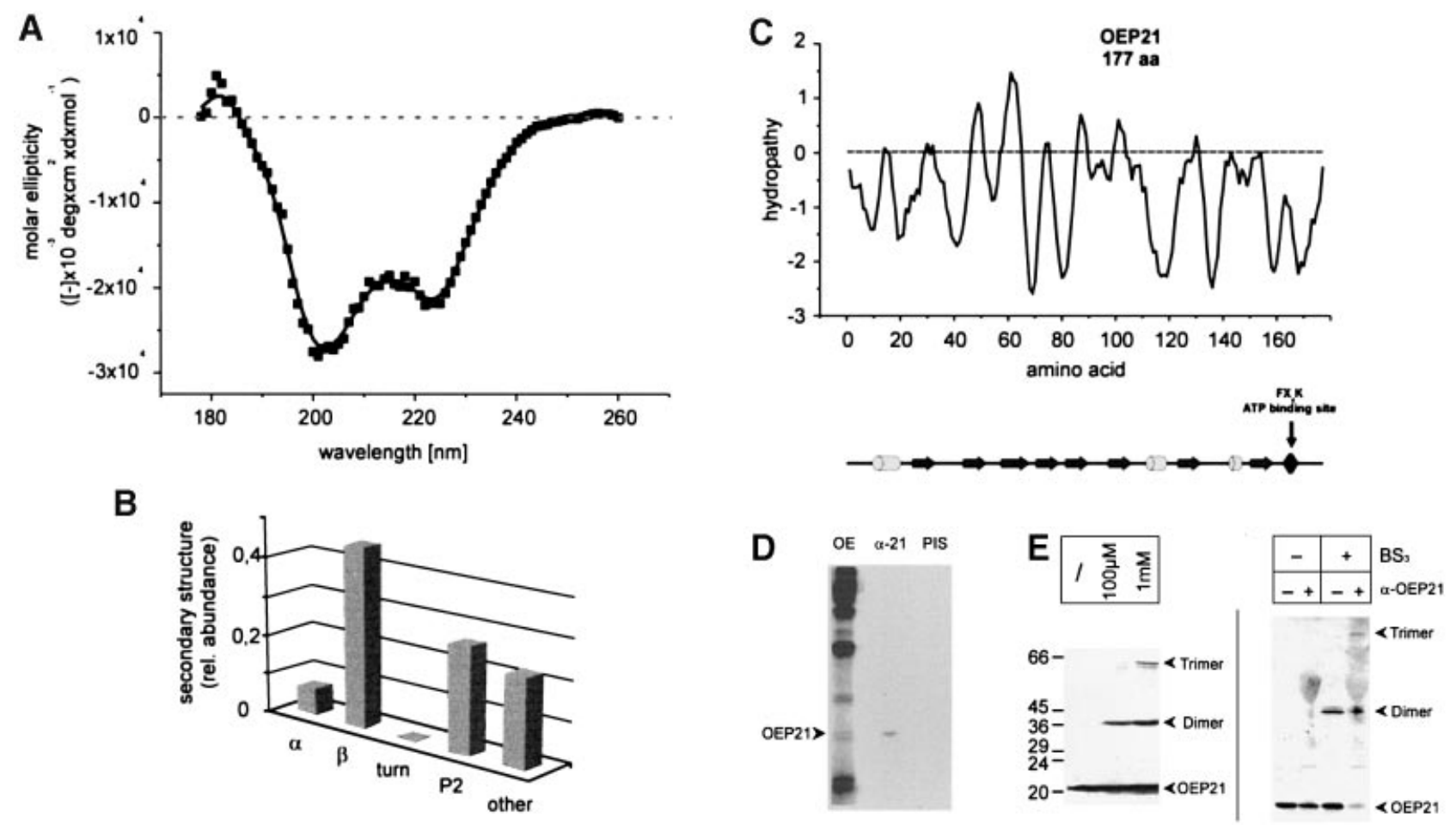

Fig. 3. Structural analysis of OEP21. (A) CD spectra of OEP21 reconstituted into liposomes. CD spectra were recorded between 180 and $250 \mathrm{~nm}$ on a Jasco 600 CD spectropolarimeter, as described in Materials and methods. (B) Relative (rel.) abundance of OEP21 secondary structure reconstituted into liposomes, according to Sreerama and Woody $(1993,1994)$. P-2, disturbed helix in the presence of two prolines. (C) Hydropathy plot (Gilbert, 1992) predicted secondary structure (Rost and Sander, 1993) of the deduced amino acid sequence of OEP21. $\beta$-sheets are shown as arrows, putative helices as cylinders. (D) Affinity labelling of outer envelope membranes by $\left[{ }^{32} \mathrm{P}\right] \mathrm{N}_{3}$-ATP in $254 \mathrm{~nm}$ UV light. Lane 1 shows total labelling of outer envelope proteins; lanes 2 and 3 show immunoprecipitations using OEP21 antiserum or pre-immune serum, respectively. A fluorogram is shown. (E) Outer envelope membranes $\left(10 \mu \mathrm{g}\right.$ of protein) were incubated with the chemical cross-linker $\mathrm{BS}^{3}$ and analysed for the formation of OEP21 oligomers after SDS-PAGE by immunoblotting (left panel). Numbers on the left indicate the position of molecular weight markers in kDa. The right panel shows an immunoprecipitation in the absence or presence of $\alpha$-OEP21 as indicated after cross-linking followed by immunoblotting and incubation with $\alpha$-OEP21.

were of similar size to those in isolated outer membranes. The thermolysin-resistant protein Toc75 and the inner envelope protein Tic110 were not degraded by thermolysin in intact chloroplasts (Figure 1E). Together, these data indicate that OEP21 exposes a protease-sensitive loop at the cytoplasmic face of the outer envelope membrane (see also below). Immunogold labelling of ultra thin sections from pea leaves $(n>100)$ also supports the chloroplast origin of OEP21 and its localization in the outer envelope (Figure 1F).

Radiolabelled OEP21 translation product was found to insert into intact chloroplasts that had either not been treated or been treated with protease to remove surfaceexposed receptor components that initiate translocation of precursor proteins (Figure 2A). The OEP21 translation product inserted slightly more effectively into proteasepretreated chloroplasts, perhaps because the accessible lipid membrane surface increases due to the removal of large exposed polypeptide epitopes. Insertion of proteins without a cleavable transit sequence is also independent of ATP (Figure 2C). In contrast, the precursor of the stromal protein SSU (small subunit of ribulose-1,5-bisphosphatecarboxylase, pSSU) requires the hydrolysis of ATP for import $(>100 \mu \mathrm{M})$ and the presence of proteasesensitive presequence receptors at the organellar surface (Figure 2B). From the results presented in Figures 1 and 2 , we conclude that OEP21 is indeed localized in the outer envelope of pea chloroplasts.

\section{Expression and structural analysis of OEP21}

In order to characterize the functional properties of OEP21, the pea protein was heterologously expressed in E.coli cells. The protein was recovered from insoluble inclusion bodies, denatured in $6 \mathrm{M}$ guanidine- $\mathrm{HCl}$ and purified further by cation exchange chromatography and size exclusion chromatography. The isolation protocol resulted in OEP21 purified to apparent homogeneity (Figure 1B, lanes 2-5). The circular dichroism (CD) spectra of the reconstituted heterologously expressed OEP21 protein show that $\beta$-sheets are the most frequent secondary structure element (Figure 3A). The CD data also allow calculation of the relative content of secondary structures $(\alpha=$ $0.11 ; \beta=0.46 ; \mathrm{P} 2=0.23$; other $=0.20)($ Figure $3 \mathrm{~B})$ (Pohlmeyer et al., 1997, 1998; Hill et al., 1998). These results are in line with the secondary structure predictions by the PHD or PSD programs (Pattern Structure Database), which both predict an $\alpha$-helix content $<15 \%$ for OEP 21 , while the predicted amount of $\beta$-sheets was $>40 \%$. Furthermore, available computer algorithms do not indicate the presence of a transmembrane $\alpha$-helix in OEP21 (Gilbert, 1992; Rost and Sander, 1993; Rost et al., 1994) (Figure 3C). From the above predictions, we obtained the putative secondary structure and hydropathy profile as outlined in Figure 3C. According to these results, OEP21 contains eight amphipatic $\beta$-strands spanning the membrane and a hydrophilic loop from about $\mathrm{G}_{107}-\mathrm{G}_{108}$ to approximately $G_{124}-G_{125}$ carrying four positive charges 
and two adjacent positive charges $\left(\mathrm{K}_{104}, \mathrm{~K}_{106}\right.$; see Figure 1A). The putative secondary structure resembles that of OMP21 from Comamonas acidovorans and other similar proteins that are characterized by eight transmembrane $\beta$-strands, large exoplasmic loops and a C-terminal domain in the periplasmic (intermembrane) space. Some of these proteins are proposed to form membrane pores (Baldermann et al., 1998). In the hydrophilic C-terminal part of the protein, we localized a potential ATP-binding site of the $\mathrm{FX}_{4} \mathrm{~K}$ type, which has a rectifying role in potassium-selective channels (D.B.McIntosh et al., 1996; Drain et al., 1998). Support for functionality of this motif comes from photoaffinity labelling with azido ATP (Figure 3D), which demonstrates that OEP21 binds ATP. In order to identify proteins in close physical proximity
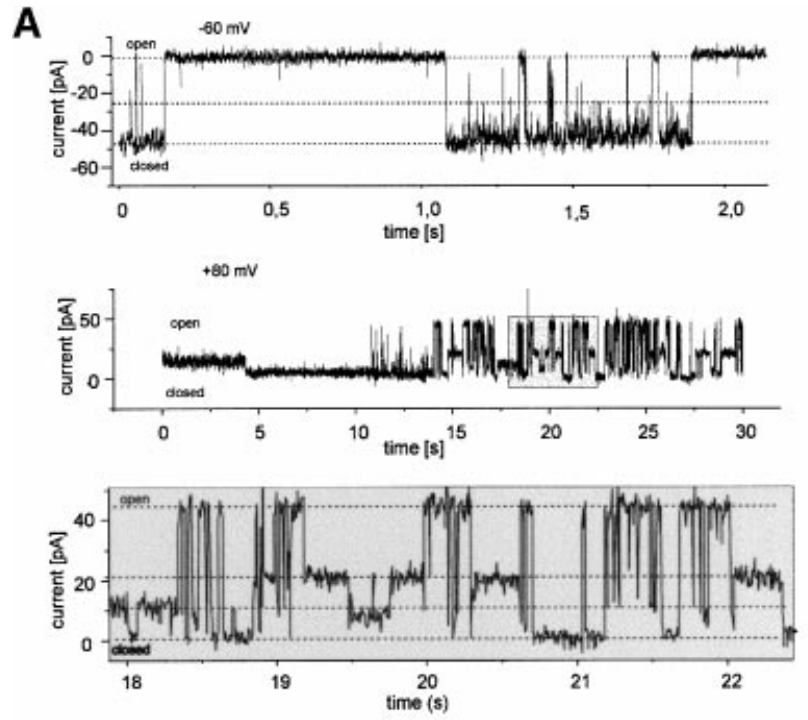

B
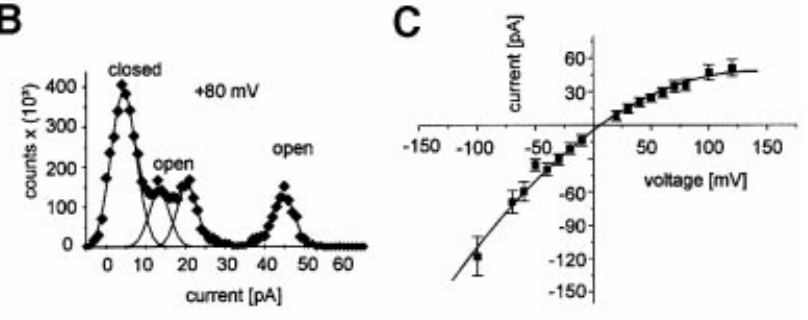

D
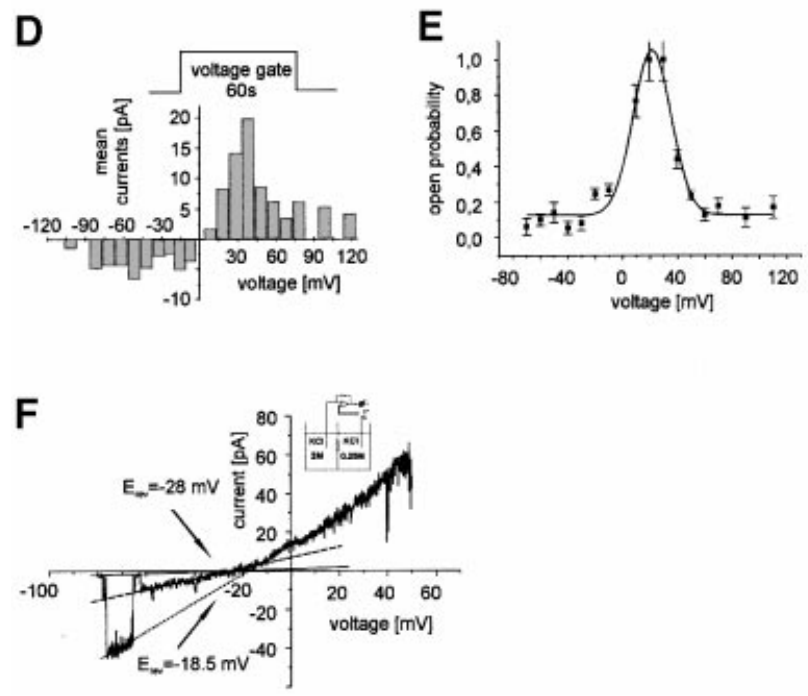

to OEP21, purified outer envelope membranes were incubated with different chemical cross-linking reagents. No partner proteins could be detected except for the formation of homo-oligomeric states of OEP21. Immunoblotting and co-immunoprecipitation experiments indicated that the dimeric form was most prominent, but trimers were also detectable at higher cross-linker concentrations (Figure 3E). How this correlates with OEP21 function remains to be established.

\section{OEP21 forms an intrinsically rectifying anion channel with subconductant states}

The data so far strongly supported our idea that OEP21 may form a solute channel. The purified protein was reconstituted into liposomes as described in detail previously (Pohlmeyer et al., 1997, 1998). After fusion of OEP21 liposomes with planar lipid bilayers, voltage-dependent single channel currents could be well resolved, provided measurements were performed in solutions with ionic strength $\geqslant 250 \mathrm{mM}$. Single channel activity was observed at both positive and negative membrane potentials (Figure 4A). The OEP21 channel displayed complex gating with multiple open channel amplitudes (Figure 4B). Direct transitions between the different open channel amplitudes were observed, indicating that these amplitudes represent subconductant states of a single channel rather than simultaneous openings or closures of independent channels with various amplitudes and rise times of gating $<200 \mu \mathrm{s}$, the time resolution of the experiment. In the histogram of the current recordings, three sublevels were clearly resolved at a holding potential of $80 \mathrm{mV}\left(\Delta \mathrm{I}_{1}=\right.$ $13.4 \mathrm{pA}, \Delta \mathrm{I}_{2}=20.4 \mathrm{pA}, \Delta \mathrm{I}_{3}=44.7 \mathrm{pA}$ ) (Figure 4B), while the number of counts for the fourth level with $\Delta \mathrm{I}_{1} \cong 29 \mathrm{pA}$ was too low to be resolved. In different independent bilayer experiments, the high conductance state of the OEP21 channel was $\Lambda=950 \pm 30 \mathrm{pS}(n>5)$ in symmetric $1 \mathrm{M} \mathrm{NaCl}$ (as deduced from Figure 4C). Frequent subconductance levels were observed at $\Lambda_{1}=$

Fig. 4. Electrophysiological properties of purified recombinant OEP21. (A) Current recordings from a bilayer containing a single copy of an active channel at a holding potential $V_{\mathrm{h}}=-60 \mathrm{mV}$ (upper) and $V_{\mathrm{h}}=$ $+80 \mathrm{mV}$ (middle). Lower panel, current recording and expanded view from the bilayer containing a single copy of an active channel at a holding potential of $V_{\mathrm{h}}=+80 \mathrm{mV}$ shown in the middle panel. The cis and trans chamber contained $1 \mathrm{M} \mathrm{NaCl}, 10 \mathrm{mM}$ MOPS-Tris $\mathrm{pH}$ 7.0. (B) All point amplitude histogram of the current trace. (C) Current-voltage relationship of the single channel deduced from single channel currents of the main conductance state in symmetric solutions of $1 \mathrm{M} \mathrm{NaCl}, 10 \mathrm{mM}$ MOPS-Tris $\mathrm{pH} 7.0$ in both compartments. Data points are an average of $n=5$ independent bilayers. Error bars represent standard deviation of the data. (D) Mean current histogram in a bilayer containing a single copy of an active channel during an applied voltage gate of $60 \mathrm{~s}$ duration with different amplitudes (symmetric buffer $1 \mathrm{M} \mathrm{NaCl}, 10 \mathrm{mM}$ MOPS-Tris pH 7.0). (E) Calculated mean open probability averaged for all open channel amplitudes. Data were calculated by dividing the averaged open channel currents measured in (D) by the maximum possible currents of the open main conductance state (B). Only mean current and open channel current data from the same bilayer were used to calculate $P_{\text {open }}$. Data points are an average of $n=3$ independent bilayers. Error bars represent standard deviation of the data. (F) Current recording from a bilayer containing a single copy of an active channel in response to a voltage sweep (increment $5 \mathrm{mV} / \mathrm{s}$ ) from 0 to $+50 \mathrm{mV}$ and from 0 to $-80 \mathrm{mV}$. The cis compartment contained $2 \mathrm{M} \mathrm{KCl}$, $10 \mathrm{mM}$ MOPS-Tris pH 7.0, and the trans compartment contained $250 \mathrm{mM} \mathrm{KCl}, 10 \mathrm{mM}$ MOPS-Tris $\mathrm{pH}$ 7.0. Dotted lines indicate the slope of two different channel conductance states. 
$430 \pm 20 \mathrm{pS}(n=5)$ and $\Lambda_{2}=280 \pm 20 \mathrm{pS}(n=5)$. In symmetric $250 \mathrm{mM} \mathrm{NaCl}$, the highest conductance of the OEP 21 channel showed a value of $\Lambda=350 \pm 10 \mathrm{pS}$ $(n>20)$. The current-voltage relationship of the open single channel was asymmetric, even in symmetric buffers on both sides of the membrane (Figure 4C), as observed in $>10$ sets of independent bilayer experiments. This shows that the OEP21 channel is intrinsically rectifying, probably due to interactions of the permeating ions with the channel pore, which presumably exhibits an asymmetric potential profile along the channel pore (see also below). Moreover, the applied fusion technique yielded OEP21 channels incorporated into the bilayer membrane with a single preferential direction, otherwise the asymmetric current-voltage relationship (Figure 4C) could not have been observed. When a voltage gate of $60 \mathrm{~s}$ was applied across an OEP21-containing bilayer, the averaged mean currents passing the OEP21 channel decreased with increasing membrane potentials (Figure 4D). This decrease was more pronounced at negative potentials than at positive potentials. The data from Figure $4 \mathrm{C}$ and $\mathrm{D}$ have been obtained from the same bilayer, therefore they may be used to calculate the mean open probability (averaged for all sublevels) of the OEP21 channel at different membrane potentials (Figure 4E). Obviously, the open probability of the recombinant reconstituted channel is high $\left(P_{\text {open }}>0.2\right)$ only in a narrow range of membrane potentials from $V_{\mathrm{m}}=$ $0 \mathrm{mV}$ to $V_{\mathrm{m}}=+50 \mathrm{mV}$, while reconstituted envelope membranes contain open OEP21 channels at $0 \mathrm{mV}$ (see below). In asymmetric buffers $(2 \mathrm{M} \mathrm{KCl} / 250 \mathrm{mM} \mathrm{KCl}$ cis/trans), the OEP21 channel revealed a reversal potential of $E_{\text {rev }}=-18.5 \pm 2.8 \mathrm{mV}\left(E_{\mathrm{Cl}^{-}}=-5 \mathrm{mV}, E_{\mathrm{K}^{+}}=\right.$ $+35 \mathrm{mV}$ ) (Figure 4F). These results demonstrate that OEP21 forms an anion-selective channel. The lower conductance states of the OEP21 channel revealed a slightly higher selectivity for cations over anions (Figure 4F). The conductance $\left(\Lambda_{1}\right)$ with $40 \%$ of the fully open channel amplitude revealed a reversal potential of $\mathrm{E}_{\mathrm{rev}}=$ $-28 \pm 3.6 \mathrm{mV}$. Conversion of the reversal potential into relative permeabilities by the Goldman-Hodgkin-Katz (GHK) approach yielded the permeability ratios of $P_{\mathrm{Cl}^{-}}-$ $P_{\mathrm{K}^{+}} \cong 3: 1$ and $P_{\mathrm{Cl}^{-}} / P_{\mathrm{K}^{+}} \cong 5: 1$, respectively. From the single channel conductance, we can estimate the approximate diameter of the aqueous OEP2 1 channel as $d_{\text {channel }} \cong 2.1 \mathrm{~nm}$ (Hille, 1968), taking into account that the conductivity of the electrolyte solution within the pore is $\sim 5 \times$ lower than in the bulk solution (Smart et al., 1997).

In bi-ionic measurements, we investigated the relative permeability of the OEP21 channel for 3-phosphoglycerate (3PGA), glucose-6-phosphate (G6P), triosephosphate (TP), $\mathrm{HPO}_{4}{ }^{2-}$ and others. All ions were able to permeate OEP21 (not shown). These measurements allowed calculation of the permeability ratios for those ions that carry a uniform charge under the experimental conditions (Table I) (Hille, 1968). Conversion of the measured reversal potentials into permeability ratios by the GHK constant field approach revealed higher permeability for the divalent anions $\mathrm{SO}_{4}{ }^{2-}$ and $\mathrm{HPO}_{4}{ }^{2-}$. The apparent higher permeability of the divalent anions implies that they interact more strongly with the OEP21 channel pore than monovalent anions.
Table I. Selectivity of the OEP21 channel

\begin{tabular}{lcc}
\hline Ion & $V_{\text {rev }}(\mathrm{mV})$ & $P_{\text {ion }} / P_{\mathrm{Cl}^{-}}$ \\
\hline $\mathrm{K}^{+\mathrm{a}}$ & -21 & $0.33 \pm 0.01$ \\
$\mathrm{~K}^{+\mathrm{b}}$ & -28 & $0.21 \pm 0.01$ \\
$\mathrm{NO}_{2}{ }^{-}$ & -20 & $1.1 \pm 0.1$ \\
$\mathrm{NO}_{3}{ }^{-2}$ & -13 & $2.4 \pm 0.4$ \\
$\mathrm{SO}_{4}{ }^{2-}$ & 3 & $3.6 \pm 1.5$ \\
$\mathrm{HPO}_{4}{ }^{2-}$ & 0 & $3.9 \pm 1.8$ \\
Malate & -23 & $0.7 \pm 0.3$ \\
\hline
\end{tabular}

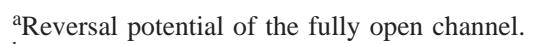

${ }^{b}$ Reversal potential of the most frequent subconductance state.

\section{Rectification and ion selectivity of the OEP21 channel are regulated by ATP/triosephosphate and other phosphates}

When $1 \mathrm{mM}$ ATP was added to the trans compartment of the bilayer containing active OEP2 1 channels, we observed a drastic change in the reversal potential and the shape of the current-voltage relationship (Figure 5A, C and D). The addition of ATP resulted in a switch of positive to negative current at $V_{\mathrm{m}}=0 \mathrm{mV}$ (Figure 5A), i.e. rectification at positive voltages (see also Figure $4 \mathrm{C}$ ) in the absence of ATP changed to rectification at negative voltages. Concomitantly, the ratio of slope conductance (a measure of the degree of rectification) of bilayers at positive $\left(V_{\mathrm{m}}\right.$ $\left.>V_{\text {rev }}\right)$ and negative $\left(V_{\mathrm{m}}<V_{\text {rev }}\right)$ membrane potentials shows that 1-5 mM ATP when added to the trans compartment is sufficient at negative potentials to decrease anion currents from the trans to the cis compartment (Figure 5B). The permeability ratios in the absence or presence of $1 \mathrm{mM}$ ATP changed from $P_{\mathrm{Cl}^{-}} / P_{\mathrm{K}^{+}} \cong 3: 1$ to $P_{\mathrm{Cl}^{-}} / P_{\mathrm{K}}{ }^{+} \cong 1: 4$, respectively. We conclude that rectification of the OEP21 channel and its selectivity are regulated by ATP in a concentration-dependent manner from one side of the membrane only. GTP revealed the same changes as ATP on the rectification and reversal potential of reconstituted OEP21 (data not shown). When ATP was added to the cis compartment under the same ionic strength conditions (opposite gradient), neither a change in reversal potential nor a change in the profile of the current-voltage relationship of the OEP21 channel was observed (see Figure 5E and F). The site specificity of this effect was observed in $>100$ independent bilayer experiments. The ATP concentration dependence of this reversal potential change follows a typical saturation isotherm (Figure 6A and $\mathrm{B})$. The data can be fitted by a two-site binding model: one high affinity binding site $\left(K_{\mathrm{b}}=148 \pm 38 \mu \mathrm{M}\right.$ ATP, $\Delta V_{\max }=23.6 \mathrm{mV}$ ) and a second lower affinity site of $K_{\mathrm{b}}=18.5 \pm 5 \mathrm{mM}$ ATP, $\Delta V_{\max }=18.4 \mathrm{mV}$.

Different phosphate-containing metabolic intermediates, i.e. 3PGA, TP, G6P, pyrophosphate $\left(\mathrm{PP}_{\mathrm{i}}\right)$ and phosphate $\left(\mathrm{P}_{\mathrm{i}}\right)$, were tested for their capacity to substitute ATP in its effect on the activity of the OEP21 channel. All tested substrates were able to change the reversal potential in a concentration-dependent manner (Figure 6D and E, Table II). However, the extent of the maximal reversal potential changes was significantly lower. The binding constants calculated for 3PGA, G6P, TP, $\mathrm{PP}_{\mathrm{i}}$ and $\mathrm{P}_{\mathrm{i}}$ were also lower than for ATP (Table II). The exception was ADP which revealed a binding affinity for OEP21 similar to ATP (Figure 6C, Table II). In all cases, the effects were 
A
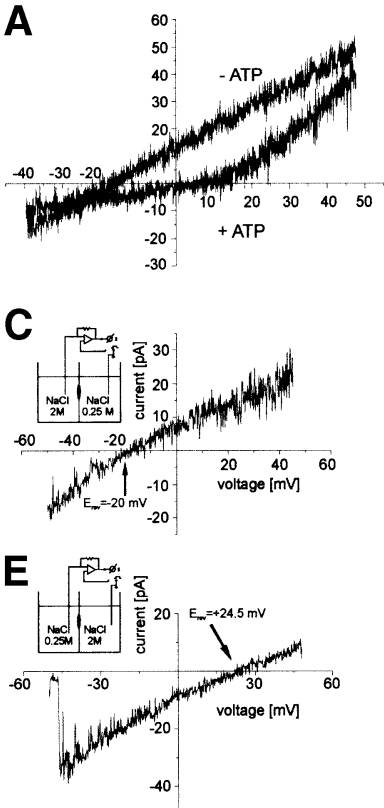

B

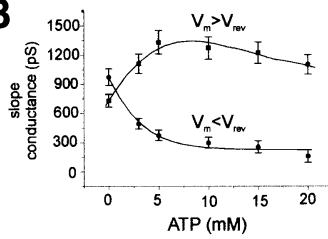

D

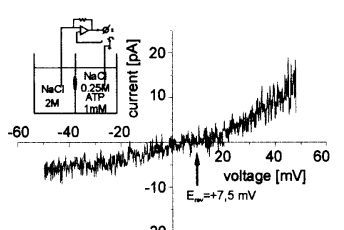

$\mathbf{F}$

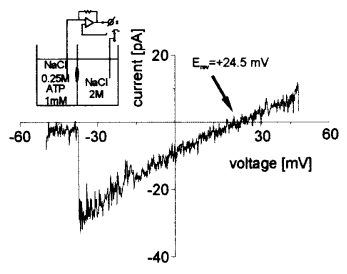

Fig. 5. Effect of ATP on the activity of the OEP21 channel.

(A) Current recording from a bilayer containing a single copy of an active channel in response to a voltage sweep (increment $10 \mathrm{mV} / \mathrm{s}$ ) from 0 to $+50 \mathrm{mV}$ and from 0 to $-40 \mathrm{mV}$. The cis compartment contained $2 \mathrm{M} \mathrm{NaCl}, 10 \mathrm{mM}$ MOPS-Tris $\mathrm{pH} \mathrm{7.0,} \mathrm{and} \mathrm{the} \mathrm{trans}$ compartment contained $250 \mathrm{mM} \mathrm{NaCl}, 10 \mathrm{mM}$ MOPS-Tris pH 7.0. Measurement in the absence (-ATP) and presence (+ ATP) of $1 \mathrm{mM}$ ATP in the trans compartment. (B) Calculated slope conductance for holding potentials $V_{\mathrm{m}}>V_{\text {rev }}$ (anion currents from cis to trans) and $V_{\mathrm{m}}$ $<V_{\text {rev }}$ (anion currents from trans to cis). (C) Current recording from a bilayer containing a single copy of an active channel in response to a voltage sweep (increment $1 \mathrm{mV} / \mathrm{s}$ ) from 0 to $+50 \mathrm{mV}$ and from 0 to $-50 \mathrm{mV}$. The cis compartment contained $2 \mathrm{M} \mathrm{NaCl}$ and the trans compartment contained $250 \mathrm{mM} \mathrm{NaCl}$. (D) Current recording from the same bilayer as in (C) after addition of $1 \mathrm{mM}$ ATP to the trans compartment. (E) Current recording from the same bilayer as in (C) and (D) after changing the buffer in the cis compartment to $250 \mathrm{mM}$ $\mathrm{NaCl}, 10 \mathrm{mM}$ MOPS-Tris $\mathrm{pH} 7.0$ and in the trans compartment to $2 \mathrm{M} \mathrm{NaCl}, 10 \mathrm{mM}$ MOPS-Tris $\mathrm{pH}$ 7.0. (F) Current recording from the same bilayer as in (C), (D) and (E) after addition of $1 \mathrm{mM}$ ATP to the cis compartment.

only observed when the effectors were added from the trans compartment. Competition experiments show that TP and, at higher concentrations, also 3PGA can reverse the effect of ATP on the reversal potential (Figure 6F and $\mathrm{G})$. In the absence of competitor, $\Delta V_{\text {rev }}$ was $24 \mathrm{mV}$ at $1 \mathrm{mM}$ ATP (Figure 6F) and $28 \mathrm{mV}$ at $2 \mathrm{mM}$ ATP (Figure 6G). $V_{\text {rev }}$ decreased with increasing competitor concentration to $\Delta V_{\text {rev }}=9 \mathrm{mV}$ at $8 \mathrm{mM}$ TP (Figure $6 \mathrm{~F}$ ) and to $8 \mathrm{mV}$ at $20 \mathrm{mM}$ 3PGA (Figure 6G). Concomitantly, the current density from the trans to the cis compartment increased significantly. Therefore, TP and 3PGA can reverse the effect of ATP on the reversal potential of OEP21. Moreover, the ion selectivity of the channel and current density from the cis to the trans compartment and vice versa are regulated by the ratio of the ATP/TP and 3PGA concentrations.

\section{Chloroplast outer membrane vesicles contain an ion channel activity with properties identical to the reconstituted OEP21}

In order to reconcile the channel activity of OEP21 described above with possible activities in the chloroplast

A

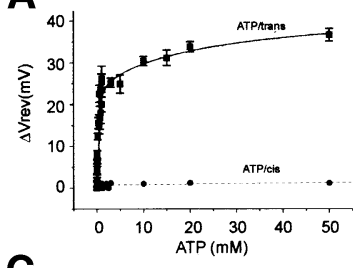

$\mathbf{C}_{20}$

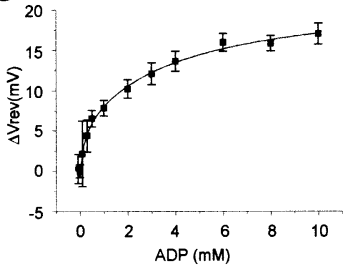

E

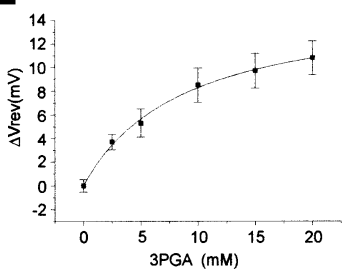

G

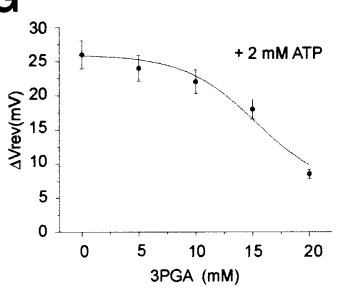

Fig. 6. Effect of different phosphate compounds on the reversal potential of the OEP21 channel. (A-E) Measurements of the reversal potential as a function of added effector concentration. Bilayers contained between one and three active copies of the OEP21 channel. The cis compartment contained $2 \mathrm{M} \mathrm{NaCl}, 10 \mathrm{mM}$ MOPS-Tris $\mathrm{pH} 7.0$, and the trans compartment contained $250 \mathrm{mM} \mathrm{NaCl}, 10 \mathrm{mM}$ MOPS-Tris $\mathrm{pH}$ 7.0. The ordinate shows the change of reversal potential after addition of the amount and type of effector (abscissa) indicated to the trans compartment of the bilayer. Where indicated, the effector was added to the cis compartment with an opposite concentration gradient (cis $250 \mathrm{mM} \mathrm{NaCl}, 10 \mathrm{mM}$ MOPS-Tris pH 7.0; trans $2 \mathrm{M} \mathrm{NaCl}, 10 \mathrm{mM}$ MOPS-Tris $\mathrm{pH}$ 7.0). Data points are averages of $n \geqslant 3$ experiments. (F and G) Competition between ATP/ GAP and ATP/3PGA. Measurements of the reversal potential as a function of added competitor concentration. Bilayers contained between one and three active copies of the OEP21 channel (cis $2 \mathrm{M}$ $\mathrm{NaCl}, 10 \mathrm{mM}$ MOPS-Tris pH 7.0; trans $250 \mathrm{mM} \mathrm{NaCl}, 10 \mathrm{mM}$ MOPS-Tris $\mathrm{pH} 7.0$ ). Data points are averages of $n \geqslant 3$ experiments. In (G), $2 \mathrm{mM}$ ATP was used instead of $1 \mathrm{mM}$ in (F) (see above).

outer envelope, we investigated the channel activity present in biochemically and morphologically well characterized outer membrane vesicles from pea chloroplasts.

Pea chloroplast outer membrane vesicles fused readily with planar bilayers, with concomitant appearance of ion channel activity. Most frequently, an anion-selective channel with $V_{\text {rev }}=-26 \mathrm{mV}, E_{\mathrm{Cl}^{-}}=-35 \mathrm{mV}$ and a conductance of $\Lambda=900 \mathrm{pS}$ in asymmetric buffer was observed as single channel activity (Figure 7A) in comparison with the recombinant protein $\left(V_{\mathrm{rev}}=-28 \mathrm{mV}, E_{\mathrm{Cl}^{-}}=\right.$ $-35 \mathrm{mV}$ ) (see below). In $<5 \%$ of the fusion events, an additional large conductant cation channel with a reversal potential of $V_{\mathrm{rev}}=+25 \mathrm{mV}\left(V_{\mathrm{K}^{+}}=+35 \mathrm{mV}, E_{\mathrm{Cl}^{-}}=\right.$ 
Table II. Binding constants for effectors that induce reversal potential changes in the reconstituted OEP21 channel and the OEP21 channel in chloroplast outer membrane vesicles

\begin{tabular}{|c|c|c|c|c|c|}
\hline Compound & $K_{\mathrm{b}}^{1}$ & $K_{\mathrm{b}}^{2}$ & $\Delta V_{\text {sat }}^{1}(\mathrm{mV})$ & $\Delta V_{\text {sat }}^{2}(\mathrm{mV})$ & $\Sigma \Delta V(\mathrm{mV})$ \\
\hline \multicolumn{6}{|l|}{ OEP21 } \\
\hline ATP & $148 \pm 38 \mu \mathrm{M}$ & $18.43 \pm 5.3 \mathrm{mM}$ & $23.6 \pm 1.9$ & $18.4 \pm 5.3$ & 42 \\
\hline ADP & $170 \pm 17 \mu \mathrm{M}$ & $4.5 \pm 1.3 \mathrm{mM}$ & $19.9 \pm 3.4$ & $8.2 \pm .1 .8$ & 28.1 \\
\hline Pyrophospate & $0.82 \pm 0.23 \mathrm{mM}$ & & $24.6 \pm 1.7$ & & 24.6 \\
\hline Phosphate & $1.67 \pm 0.18 \mathrm{mM}$ & & & & 26.3 \\
\hline Glucose-6-phosphate & $8.3 \pm 3.1 \mathrm{mM}$ & & $9.1 \pm 1.0$ & & 9.1 \\
\hline 3-Phosphoglycerate & $8.7 \pm 1.0 \mathrm{mM}$ & & $15.5 \pm 0.7$ & & 15.5 \\
\hline Glycerol-aldehyde-phosphate & $1.48 \pm 0.7 \mathrm{mM}$ & & $11.8 \pm 2.5$ & & 11.8 \\
\hline \multicolumn{6}{|l|}{ Chloroplast outer membrane vesicles } \\
\hline ATP & $40 \pm 15 \mu \mathrm{M}$ & & & & 22 \\
\hline Glycerol-aldehyde-phosphate & $2.2 \pm 1 \mathrm{mM}$ & & & & 22 \\
\hline
\end{tabular}

A
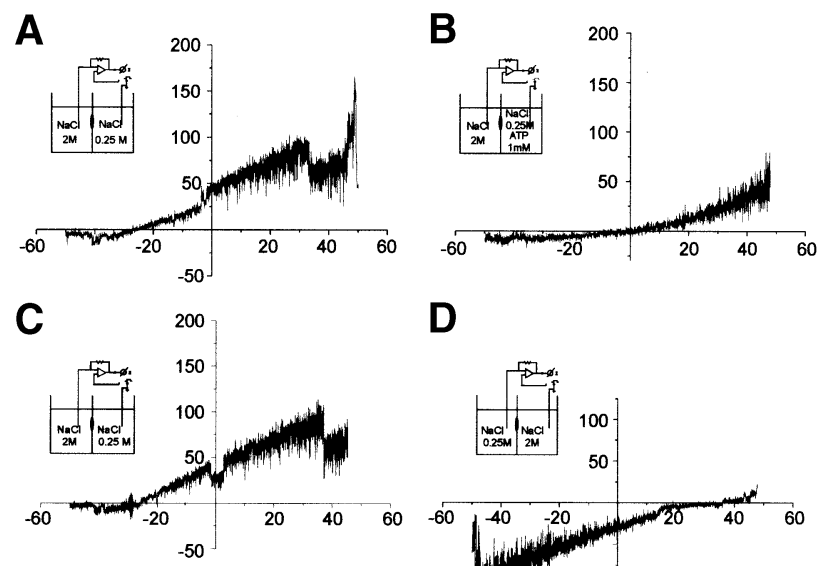

D
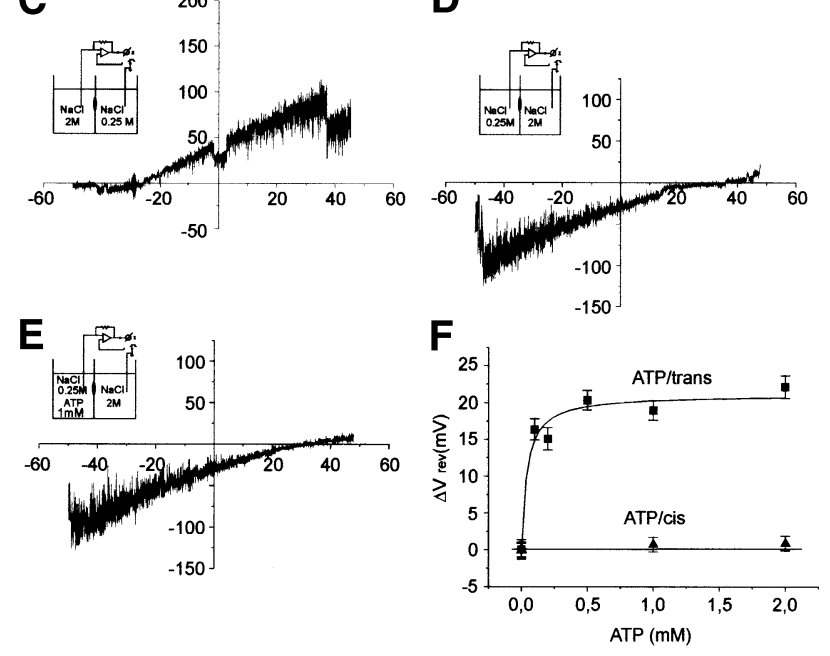

Fig. 7. Outer membrane vesicles contain an anion channel with properties identical to the reconstituted recombinant OEP21.

(A and B) Current recording from a bilayer after fusion of outer membrane vesicles from pea chloroplasts. Activity of the channel(s) in response to a voltage sweep (increment $5 \mathrm{mV} / \mathrm{s}$ ) from 0 to $+50 \mathrm{mV}$ and from 0 to $-50 \mathrm{mV}$. The cis compartment contained $2 \mathrm{M} \mathrm{NaCl}$, $10 \mathrm{mM}$ MOPS-Tris $\mathrm{pH}$ 7.0, and the trans compartment contained $250 \mathrm{mM} \mathrm{NaCl}, 10 \mathrm{mM}$ MOPS-Tris pH 7.0. Measurement in the absence (A) and presence (B) of $1 \mathrm{mM}$ ATP in the trans compartment. (C) Current recording from the same bilayer as in (A) and (B) after removal of ATP from the trans compartment. Voltage sweep (increment $1 \mathrm{mV} / \mathrm{s}$ ) from 0 to $+50 \mathrm{mV}$ and from 0 to $-50 \mathrm{mV}$. The cis compartment contained $2 \mathrm{M} \mathrm{NaCl}, 10 \mathrm{mM}$ MOPS-Tris pH 7.0, and the trans compartment contained $250 \mathrm{mM} \mathrm{NaCl}, 10 \mathrm{mM}$ MOPSTris pH 7.0. (D) Current recording from the same bilayer as in (A), (B) and (C) after changing the concentration gradient to the opposite direction. Voltage sweep (increment $1 \mathrm{mV} / \mathrm{s}$ ) from 0 to $+50 \mathrm{mV}$ and from 0 to $-50 \mathrm{mV}$. The cis compartment contained $250 \mathrm{mM} \mathrm{NaCl}$, $10 \mathrm{mM}$ MOPS-Tris $\mathrm{pH} 7.0$, and the trans compartment contained $2 \mathrm{M}$ $\mathrm{NaCl}, 10 \mathrm{mM}$ MOPS-Tris $\mathrm{pH}$ 7.0. (E) Current recording from the same bilayer as in (A-D) with addition of $1 \mathrm{mM}$ ATP to the cis compartment. Voltage sweep (increment $5 \mathrm{mV} / \mathrm{s}$ ) from 0 to $+50 \mathrm{mV}$ and from 0 to $-50 \mathrm{mV}$. The cis compartment contained $250 \mathrm{mM} \mathrm{NaCl}$ and the trans compartment contained $2 \mathrm{M} \mathrm{NaCl}$. (F) Measurement of the reversal potential as a function of different ATP concentrations added to the trans or cis compartment, respectively.

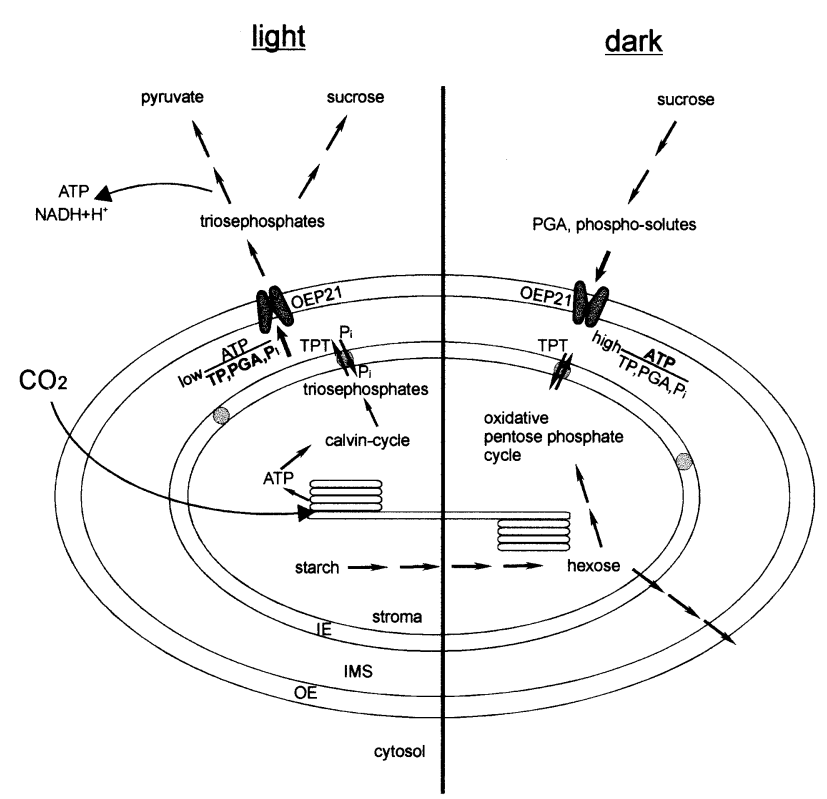

Fig. 8. Working model of OEP21 involvement and regulation of triosephosphate transport between chloroplast and cytosol.

$-35 \mathrm{mV}$ ) and a conductance of $\Lambda=1.1 \mathrm{nS}$ was also present (details not shown). When ATP $(1 \mathrm{mM})$ was added to the trans compartment of bilayers containing only the anion channel activity from pea chloroplast outer membrane vesicles, we observed a drastic change in the reversal potential (see Figure 7A and B). After washing the ATP out of the compartment, the original conductance properties were again obtained (compare Figure 7A and C). We then reversed the $\mathrm{NaCl}$ concentration in the cis and trans chamber, i.e. $0.25 \mathrm{M} \mathrm{NaCl}$ cis versus $2 \mathrm{M} \mathrm{NaCl}$ trans (Figure 7D). Addition of $1 \mathrm{mM}$ ATP to the cis compartment had no effect on the reversal potential and conductance properties of OEP21 from envelopes (Figure 7E), demonstrating again that ATP can bind to one side of the channel and exert its effects from the trans side only. The change in the conductances of envelope OEP21 is a function of the ATP concentration (Figure 7F), and half-maximal changes are reached at $\sim 70 \mu \mathrm{M}$ ATP. We also tested whether TP and 3PGA have a similar effect on the reversal potential of the anion channel in the chloroplast outer membrane vesicles and observed qualitatively the same changes as described above in detail for the reconstituted OEP21 channel (Table II). 
The general similarity of functional properties of reconstituted OEP21 and the anion channel in outer membrane vesicles from pea chloroplasts strongly indicates that both channels are most likely to be identical. Since it is known that the pea chloroplast outer membrane vesicles are isolated in a right-side-out orientation (Waegemann et al., 1992), and the applied fusion technique exposes the internal side of the vesicles towards the trans compartment (Zimmerberg et al., 1980; Niles and Cohen, 1987; Niles et al., 1989; Cohen and Niles, 1993), we can now conclude that the trans bilayer compartment refers to the intermembrane space of the chloroplast. Thus, in vivo, the ATP/triosephosphate binding sites of the OEP21 solute channels are located in the intermembrane space between the two membranes.

\section{Discussion}

The electrophysiological results obtained with outer membrane vesicles from pea chloroplasts revealed that two types of channel activities were detectable after fusion into planar bilayers: first, a cation-selective channel (not further characterized), and secondly, an anion-selective channel with properties almost identical to those of reconstituted recombinant OEP21. In the case of both reconstituted recombinant OEP21 and outer envelope membranes, we observed site-specific effects of low concentrations of ATP and other phosphates on the channel activity from the trans side only. This demonstrates that in both cases the anion-selective channels were incorporated into the planar bilayer with a single preferred orientation. For reconstituted OEP21, this preferred incorporation is also corroborated by the asymmetric current-voltage relationship of the single open channel. Similar unidirectional incorporation of OMP32 from C.acidovarans and concomitant asymmetric open channel characteristics have been observed previously (Mathes and Engelhardt, 1998). Osmotically-induced fusion of OEP21 proteoliposomes or chloroplast outer membrane vesicles with planar bilayers results in an exposure of protein epitopes localized on the inside of the vesicle towards the trans compartment (Zimmerberg et al., 1980; Akabas et al., 1984; Cohen et al., 1984). We conclude that the ATP binding site of OEP21 from chloroplasts is located in the intermembrane space. This site is probably located at the $\mathrm{C}$-terminal part of the protein and is presumably of the $\mathrm{FX}_{4} \mathrm{~K}$ type $\left(\mathrm{F}_{164}-\right.$ $\mathrm{X}_{4}-\mathrm{K}_{169}$ ) (see Figure 1) (D.B.McIntosh et al., 1996; Drain et al., 1998). When ATP binds to the OEP21 channel, the reversal potential changes drastically towards positive voltages and the direction of the current rectification changes to the opposite direction. The mitochondrial VDAC and PorB from Neisseria have also been shown to interact with purine nucleoside triphosphates, which caused a shift in the voltage dependence of the open probability and the ion selectivity (Rudel et al., 1996).

Our measurements show that anions such as $\mathrm{HPO}_{4}{ }^{2-}$, $\mathrm{PP}_{\mathrm{i}}$, 3PGA, G6P and TP have a high affinity for the OEP21 channel; however, the bi-ionic measurements in particular clearly indicate that these solutes are also permeant. Although our data for ATP and other nucleoside tri- and di-phosphates do not directly allow a similar conclusion to be drawn, we propose that these solutes (ATP has a cross-section of $\sim 1.85 \times 0.45 \mathrm{~nm}$ ) should be able to pass through the $\sim 2.1 \mathrm{~nm}$ wide anion-selective channel. Carbohydrates synthesized from carbon dioxide during photosynthesis are exported from chloroplasts generally as TP (glyceraldehyde-3-phosphate, dihydroxyacetonephosphate) or 3PGA in a strict counter-exchange with phosphate by the inner envelope-localized TPT (Flügge, 1998). TPs are then converted to sucrose in the cytosol, which is the main site of carbohydrate storage in heterotrophic plant organs. The TPT functions as an ATPindependent facilitator. The transport direction is therefore controlled solely by the concentration ratios of $\mathrm{TP}$ and 3PGA to phosphate inside versus outside of the organelle. But where is the outside of the organelle? Until recently, a concept of free diffusion of low molecular weight solutes anticipated the non-selective extrusion from the intermembrane space and the cytosol. Consequently, no differences in metabolite concentration should exist between both soluble compartments. In our opinion, this seems unlikely for several reasons: (i) in analogy to Gram-negative bacteria, which represent the progenitor of plastids (Margulis, 1970; Gray, 1993), the intermembrane space is homologous to the periplasmic space, a compartment with its own biochemical function; (ii) a few selective solute channels have already been described in the chloroplastic outer envelope (Pohlmeyer et al., 1997, 1998); and (iii) the outer envelope and the intermembrane space compartment could function as a buffer zone with additional regulatory properties to mediate between chloroplast and cytosol metabolism. This is supported by our observation that OEP21 is the only solute channel that is detected regularly in an open state when isolated envelope membranes are fused with planar bilayers (Figure 7). The OEP24 channel, which is also permeated by TP and other anions, seems to be closed under these conditions. Although the open probability of reconstituted OEP24 is highest at $0 \mathrm{mV}$, it seems physiologically sensible that permeability and gating of the OEP24 channel and other outer membrane channels is indeed controlled by metabolites. Consequently, these channels would be in a nonfunctional conformation at $0 \mathrm{mV}$. Then solute flux across the outer envelope membrane by channel proteins with overlapping substrate specificity will be monitored and regulated by the presence and ratio of the respective solutes.

In spinach leaves, TP concentrations vary between $0.2 \mathrm{mM}$ in the stroma of chloroplasts and $0.6 \mathrm{mM}$ in the cytosol, while 3PGA is at $>4 \mathrm{mM}$ in each compartment (Leidreiter et al., 1995). The concentration of free phosphate is $\sim 7 \mathrm{mM}$ in the stroma of spinach chloroplasts and 5-10 $\mathrm{mM}$ in the cytosol (Stitt et al., 1980). In the light, TP are exported from the stroma across the inner envelope into the interenvelope space by the TPT in a strict counterexchange with phosphate. The actual concentration of both solutes in the intermembrane space together with 3PGA might reach between 10 and $15 \mathrm{mM}$ under these conditions and favour an outward-rectifying OEP21 channel, i.e. efflux of TP. In the dark, carbon is no longer exported as TP and 3PGA but as hexoses (Flügge, 1998). Furthermore, TP concentrations drop rapidly in the dark and the ratio of ATP to phospho solutes increases, resulting in an inward-rectifying OEP21 channel with a less pronounced anion selectivity (Figure 8).

The channel properties of OEP 21 in the presence of 
$1 \mathrm{mM}$ ATP can be reversed by the addition of $10 \mathrm{mM}$ TP or 3PGA (see Figure 6). This effect can be explained in two ways: first, ATP is displaced from its binding site by the phospho solute. We think that this is unlikely because the apparent binding constant (Table II) for ATP is between 70 and $150 \mu \mathrm{M}$, while those for the phospho solutes are 10 - to 50-fold higher. Secondly, in the presence of $\sim 1 \mathrm{mM}$ ATP (as present in vivo), the nucleotide binding site would always be occupied by ATP, while phospho solutes might bind to another site with a lower affinity. In the primary structure of OEP21, two clusters with an unusually high content of positively charged amino acids are located at $\mathrm{R}_{6}-\mathrm{R}_{23}$ (six positive residues out of 17) and $\mathrm{R}_{76}-\mathrm{R}_{90}$ (six positive residues out of 14). These regions of high positive charge density could be important for the binding of phospho solutes and hence the direction of rectification of the OEP21 channel. The change in the reversal potential can therefore be explained by the shielding of these positive charges in the channel vestibule.

It seems physiologically reasonable to control the OEP21 channel properties from the intermembrane space, because fluctuation of metabolite transport across the inner membrane probably leads to pronounced concentration changes in this extremely small compartment.

We propose a new concept that defines the role of the chloroplastic outer envelope not as a non-specific sieve with a certain cut-off limit, but as a membrane actively engaged in selective solute transport by distinct channel proteins. Gating properties and channel characteristics not only of OEP21 but probably also of other channels as well are modulated by biosynthetic pathway intermediates from the chloroplast and the cytosol. We conclude that the chloroplastic outer envelope serves as a regulatory surface between the organelle and the cell.

\section{Materials and methods}

\section{cDNA cloning and overexpression}

N-terminal and internal sequence information was obtained from untreated samples or after endoproteinase Glu-C (Roche Mannheim, Germany) digestion of SDS-PAGE-purified OEP21 of chloroplastic outer envelope membranes from pea (Cleveland, 1983). The deduced nucleotide sequence was used as a template to synthesize digoxigeninlabelled oligonucleotides. A pea cDNA expression library (UniZAPXR, Stratagene, La Jolla, CA) was screened with these probes, resulting in the isolation of peacOEP21. Both strands were sequenced (Sanger et al., 1977). PeacOEP21 was used to synthesize a random-primed digoxigeninlabelled probe by PCR, according to the manufacturer's recommendations (Roche Mannheim, Germany). A pea genomic DNA library (LambdaDash II, Stratagene) was screened to isolate a full-length clone peagOEP21. Phage DNA containing peagOEP21 was prepared (Sambrook et al., 1989) and used directly for DNA sequencing, according to the manufacturer's protocol (Applied Biosystems, Weiterstadt, Germany). The DNA sequence reported in this study has the DDBJ/EMBL/GenBank accession No. AJ009987. The missing start methionine together with an NdeI site was introduced into peacOEP21 by PCR. The PCR product was digested with NdeI and XhoI and ligated into pET21b (Novagen, Madison, WI), resulting in peacOEP21pet. Our cloning resulted in a coding sequence for OEP21 without additional amino acids or a tag to facilitate purification. Overexpression was carried out after transforming E.coli BL21(DE3) cells (Novagen). Recombinant OEP21 was recovered from insoluble inclusion bodies (Paulsen et al., 1990).

\section{Purification of recombinant protein}

For further purification, the protein was dissolved in $6 \mathrm{M}$ guanidine$\mathrm{HCl}$, diluted in $4 \mathrm{M}$ urea, $40 \mathrm{mM}$ HEPES-KOH $\mathrm{pH} 7.9$, and passed over a cation-exchange resin (POROS 20SP, Perseptive Biosystems) from which it eluted at $\sim 200 \mathrm{mM} \mathrm{NaCl}$. OEP21 was purified further by gel filtration over a Superdex75 column (Amersham Pharmacia, Freiburg, Germany).

\section{Isolation of organelles and membrane vesicles}

Pea plants (Pisum sativum, var. Golf) were grown in a growth chamber and used for the isolation of intact, silica sol-purified chloroplasts as described before (Waegemann and Soll, 1991). Envelope membranes were separated and purified from hypertonically treated chloroplasts (Keegstra and Youssif, 1986). The thylakoids were washed at least twice $(50 \mathrm{mM} \mathrm{NaP}$ buffer pH 7.4 and $10 \mathrm{mM} \mathrm{NaCl}$ ) before further use. Plastids from etiolated leaves, roots or stems were isolated as in Schindler and Soll (1986). Mitochondrial membranes were purified from potato mitochondria (Braun and Schmitz, 1992).

\section{Urea treatment of outer membrane vesicles}

Outer membrane vesicles equivalent to $20 \mu \mathrm{g}$ of total protein were centrifuged at $160000 \mathrm{~g}$ for $10 \mathrm{~min}$ and the pellet was resuspended in extraction buffer ( $25 \mathrm{mM}$ HEPES-KOH pH 7.6, $5 \mathrm{mM} \mathrm{MgCl}$ ). After addition of 1 vol. of $8 \mathrm{M}$ urea in buffer, the vesicles were incubated for $10 \mathrm{~min}$ on ice, separated into soluble and insoluble fractions by centrifugation as above and analysed by SDS-PAGE and immunoblotting.

\section{Chemical cross-linking}

Outer envelope membranes equivalent to $20 \mu \mathrm{g}$ of protein were sedimented at $160000 \mathrm{~g}$ for $10 \mathrm{~min}$ and resuspended in $25 \mathrm{mM}$ HEPES$\mathrm{KOH} \mathrm{pH} \mathrm{7.6,} 5 \mathrm{mM} \mathrm{MgCl}_{2}$. After addition of 0.1 or $1 \mathrm{mM}$ bis[sulfosuccinimidyl]suberate $\left(\mathrm{BS}^{3}\right)$, or buffer, cross-linking was allowed for $15 \mathrm{~min}$ on ice. The reaction mixture was centrifuged at $160000 \mathrm{~g}$ for $10 \mathrm{~min}$, and the pellet was resuspended in Laemmli buffer and submitted to SDS-PAGE and immunoblotting.

\section{Immunoprecipitation assays}

Immunoprecipitation with $\alpha$-OEP21 or pre-immune serum was carried out as described in Mason et al. (1988).

\section{Chloroplast protein translocation assays}

Translocation assays contained chloroplasts equivalent to $15 \mu \mathrm{g}$ of chlorophyll in $100 \mu \mathrm{l}$ of import buffer $[330 \mathrm{mM}$ sorbitol, $50 \mathrm{mM}$ HEPES-KOH pH 7.6, $3 \mathrm{mM} \mathrm{MgCl} 2,10 \mathrm{mM}$ methionine, $10 \mathrm{mM}$ cysteine, $20 \mathrm{mM}$ potassium gluconate, $10 \mathrm{mM} \mathrm{NaHCO} 3,0.2 \%$ (w/v) bovine serum albumin (BSA)] and 1-10\% of reticulocyte lysate in vitro synthesized ${ }^{35} \mathrm{~S}$-labelled protein. Translocation reactions were initiated by the addition of organelles and were allowed to continue for $20 \mathrm{~min}$ at $25^{\circ} \mathrm{C}$. Chloroplasts were recovered from the translocation assay by centrifugation through a $40 \%(\mathrm{v} / \mathrm{v})$ Percoll cushion and further treated as detailed before (Waegemann and Soll, 1991). Treatment of chloroplasts with the protease thermolysin either before or after a translocation experiment was carried out as described (May and Soll, 1998). ATP was removed from the translocation product by the addition of hexokinase and $2 \mathrm{mM}$ glucose (Seedorf et al., 1995).

\section{Reconstitution of OEP21 into small unilamellar liposomes}

Small unilamellar liposomes were obtained from purified azolectin (Sigma, type IVS) as described (Hinnah et al., 1997). Purified OEP21 was resuspended in $80 \mathrm{mM}$ Mega-9, $6 \mathrm{M}$ urea, $10 \mathrm{mM}$ MOPS-Tris $\mathrm{pH} 7.0$, mixed with the preformed liposomes and reconstituted by the dialysis technique (Hinnah et al., 1997; Hill et al., 1998). The lipid to protein ratio was adjusted to $10 \mathrm{mg} / \mathrm{ml}$ lipid:0.1 $\mathrm{mg} / \mathrm{ml}$ protein at a lipid concentration of $20 \mathrm{mg} / \mathrm{ml}$.

$\mathrm{CD}$ spectra were measured at $20^{\circ} \mathrm{C}$ using a Jasco-J-600A spectropolarimeter as described (Hinnah et al., 1997). Samples contained in a $100 \mu 1 /$ $1 \mathrm{~mm}$ pathlength cuvette were adjusted to the same protein concentration $(100 \pm 30 \mu \mathrm{g} / \mathrm{ml})$ and spectra were averaged $(n=30)$ to improve the signal to noise ratio.

\section{Electrophysiological measurements}

Planar lipid bilayers were produced by using the painting technique (Mueller et al., 1962; Miller and White, 1984). A solution of $50 \mathrm{mg} / \mathrm{ml}$ $\mathrm{L}-\alpha$-azolectin in $n$-decan was applied to a hole (100-200 $\mu \mathrm{m}$ diameter) in a Teflon septum, separating the two bath chambers (total volume $\sim 3 \mathrm{ml}$ each) that were equipped with magnetic stirrers. The resulting bilayers had a typical capacitance of $\sim 0.5 \mu \mathrm{F} / \mathrm{cm}^{2}$ and a resistance of $>100 \mathrm{G} \Omega$. The noise was $\sim 1 \mathrm{pA}$ (r.m.s.) at $5 \mathrm{kHz}$ bandwidth. After a stable bilayer was formed in symmetric solutions of $250 \mathrm{mM} \mathrm{KCl}$, $10 \mathrm{mM}$ MOPS-Tris $\mathrm{pH} 7.0$, the solution of the cis chamber was changed to asymmetric concentrations (cis chamber: $2 \mathrm{M} \mathrm{KCl}, 10 \mathrm{mM} \mathrm{CaCl}_{2}$, $10 \mathrm{mM}$ MOPS-Tris $\mathrm{pH}$ 7.0). When sodium salts of effectors were used, 
$\mathrm{KCl}$ was substituted by $\mathrm{NaCl}$. The liposomes were added to the cis compartment directly below the bilayer through the tip of a micropipette to allow the flow of the liposomes across the bilayer. If necessary, the solution in the cis chamber was stirred to promote fusion. After fusion, the electrolytes were changed to the final composition by perfusion. The $\mathrm{Ag} / \mathrm{AgCl}$ electrodes were connected to the chambers by $2 \mathrm{M} \mathrm{KCl}$-agar bridges. The electrode of the trans compartment was connected directly to the headstage of a current amplifier (EPC 7, List Medical). Reported membrane potentials refer to the trans compartment. The amplified currents were digitized at a sampling interval of $0.2 \mathrm{~ms}$ and fed into a Digidata1200 A/D converter (Axon Instruments, Foster City, CA) to store on the hard disk of an IBM-compatible PC. For analysis, a Windows ${ }^{\text {TM}}$-based analysis software ('SCIP', single channel investigation program) developed in our laboratory was used in combination with Origin 5.0 (Microcal Software Inc.).

\section{Miscellaneous methods}

An antiserum was raised in a rabbit against heterologously expressed OEP21 (Harlow and Lane, 1988). Protein was determined by the method of Lowry et al. (1951) using BSA as standard. Chlorophyll was determined as described (Arnon, 1949).

\section{Acknowledgements}

We thank C.Glockmann and M.Motzkus for excellent technical assistance. This work was supported by the Deutsche Forschungsgemeinschaft and The Fonds der Chemischen Industrie.

\section{References}

Akabas,M.H., Cohen,F.S. and Finkelstein,A. (1984) Separation of the osmotically driven fusion event from vesicle-planar membrane attachment in a model system for exocytosis. J. Cell Biol., 98, 1063-1071.

Arnon,D.J. (1949) Copper enzymes in isolated chloroplasts. Polyphenoloxidase in Beta vulgaris. Plant Physiol., 24, 42-45.

Baldermann,C., Lupas,A., Lubieniecki,J. and Engelhardt,H.J. (1998) The regulated outer membrane protein Omp21 from Comamonas acidovorans is identified as a member of a new family of eightstranded $\beta$-sheet proteins by its sequence and properties. Bacteriology, 180, 3741-3749.

Benz,R. (1994) Permeation of hydrophilic solutes through mitochondrial outer membranes: review on mitochondrial porins. Biochim. Biophys. Acta, 1197, 167-196.

Bölter,B., Soll,J., Schulz,A., Hinnah,S. and Wagner,R. (1998) Origin of a chloroplast protein importer. Proc. Natl Acad. Sci. USA, 95, $15831-15836$.

Braun,H.P. and Schmitz,U.K. (1992) Affinity purification of cytochrome $c$ reductase from potato mitochondria. Eur. J. Biochem., 208, 761-767.

Cleveland,P.W. (1983) Peptide mapping in one dimension by limited proteolysis of sodium dodecylsulfate solubilized proteins. Methods Enzymol., 96, 675-678.

Cohen,F.S. and Niles,W.D. (1993) Reconstituting channels into planar membranes: a conceptual framework and methods for fusing vesicles to planar bilayer phospholipid membranes. Methods Enzymol., 220, 50-68.

Cohen,F.S., Akabas,M.H., Zimmerberg,J. and Finkelstein,A. (1984) Parameters affecting the fusion of unilamellar phospholipid vesicles with planar bilayer membranes. J. Cell Biol., 98, 1054-1062.

Delcour,A.H. (1997) Function and modulation of bacterial porins: insights from electrophysiology. FEMS Microbiol. Lett., 151, 115-123.

Drain,P., Li,L. and Wang,J. (1998) KATP channel inhibition by ATP requires distinct functional domains of the cytoplasmic $\mathrm{C}$ terminus of the pore-forming subunit. Proc. Natl Acad. Sci. USA, 95, 13953-13958.

Flügge,U.I. (1998) Metabolite transporters in plastids. Curr. Opin. Plant Biol., 1, 201-206.

Fujiki,Y., Hubbard A.L., Fowler,S. and Lazarow,P.B. (1982) Isolation of intracellular membranes by means of sodium carbonate treatment: application to endoplasmatic reticulum. J. Cell Biol., 93, 97-102.

Gilbert,R.J. (1992) Protein structure prediction from predicted residue properties utilizing a digital encoding algorithm. J. Mol. Graph., 10, $112-119$.

Gray,M.W. (1993) Origin and evolution of organelle genomes. Curr. Opin. Genet. Dev., 3, 884-890.

Harlow,E. and Lane,D. (1988) Antibodies: A Laboratory Manual. Cold Spring Harbor Laboratory Press, Cold Spring Harbor, NY.
Hill,K., Model,K., Ryan,M.T., Dietmeier,K., Martin,F., Wagner,R. and Pfanner,N. (1998) Tom40 forms the hydrophilic channel of the mitochondrial import pore for preproteins. Nature, 395, 516-521.

Hille,B. (1968) Pharmacological modifications of the sodium channels of frog nerve. J. Gen. Physiol., 51, 199-219.

Hinnah,S., Hill,K., Wagner,R., Schlicher,T. and Soll,J. (1997) Reconstitution of a chloroplast protein import channel. EMBO J., 16, 7351-7360.

Iyer,R. and Delcour,A.H. (1997) Complex inhibition of OmpF and OmpC bacterial porins by polyamines. J. Biol. Chem., 272, 18595-18601.

Jiang,X., Payne,M.A., Cao,Z., Foster,S.B., Feix,J.B., Newton,S.M. and Klebba,P.E. (1997) Ligand-specific opening of a gated-porin channel in the outer membrane of living bacteria. Science, 276, 1261-1264.

Keegstra,K. and Youssif,A.E. (1986) Isolation and characterization of chloroplast envelope membranes. Methods Enzymol., 118, 316-325.

Keller,T.A., Ferenci,T., Prilipov,A. and Rosenbusch,J.P. (1994) Crystallization of monodisperse maltoporin from wild type and mutant strains of various enterobacteriaceae. Biochem. Biophys. Res. Commun., 199, 767-771.

Kinnally,K.W., Lohret,T.A., Campo,M.L. and Mannella,C.A. (1996) Perspectives on the mitochondrial multiple conductance channel. J. Bioenerg. Biomembr., 28, 115-123.

Klebba,P.E. and Newton,S.M. (1998) Mechanisms of solute transport through outer membrane porins: burning down the house. Curr. Opin. Microbiol., 1, 238-247.

Leidreiter,K., Kruse,A., Riens,B., Winter,H., Lohaus,G., Robinson,D., Heineke,D. and Heldt,H.W. (1995) Subcellular compartmentation of metabolites in plant cells. In Mathis,P. (ed.), Photosynthesis: From Light to Biosphere. Kluwer Academic, Dordrecht, The Netherlands, Vol. 5, pp. 499-502.

Lowry,O.H., Rosebrough,N.J., Farr,A.L. and Randell,R.J. (1951) Protein measurement with the folin phenol reagent. J. Biol. Chem., 193, 265-275.

Margulis,L. (1970) Origin of Eukaryotic Cells. Yale University Press, New Haven, CT.

Martin,W. and Muller,M. (1998) The hydrogen hypothesis for the first eukaryote. Nature, 392, 37-41.

Mathes,A. and Engelhardt,H. (1998) Nonlinear and asymmetric open channel characteristics of an ion-selective porin in planar membranes. Biophys. J., 75, 1255-1262.

Mason,H.S., Guerro,D., Boyer,J.S. and Mullet,J.E. (1980) Proteins homologous to leaf glycoproteins are abundant in stem of darkgrown soybean seedlings. Analysis of proteins and cDNAs. Plant Mol. Biol., 11, 845-856.

May,T. and Soll,J. (1998) Positive charges determine the topology and functionality of the transmembrane domain in the chloroplastic outer envelope protein Toc34. J. Cell Biol., 141, 895-904.

McIntosh,D.B., Woolley,D.G., Vilsen,B. and Andersen,J.P. (1996) Mutagenesis of segment 487Phe-Ser-Arg-Asp-Arg-Lys492 of sarcoplasmic reticulum $\mathrm{Ca}^{2+}$-ATPase produces pumps defective in ATP binding. J. Biol. Chem., 271, 25778-25789.

McIntosh,T.J., Simon,S.A., Vierling,P., Santaella,C. and Ravily,V. (1996) Structure and interactive properties of highly fluorinated phospholipid bilayers. Biophys J., 71, 1853-1868.

Miller,C. and White,M.M. (1984) Dimeric structure of single chloride channels from Torpedo electroplax. Proc. Natl Acad. Sci USA, 81, 2772-2775.

Mueller,P., Rudin,D.O., Tien,H. and Wescott,W.C. (1962) Reconstitution of cell membrane structure in vitro and its transformation into an excitable system. Nature, 194, 979-980.

Nikaido,H. (1993) Transport across the bacterial outer membrane. J. Bioenerg. Biomembr., 25, 581-589.

Niles,W.D. and Cohen,F.S. (1987) Video fluorescence microscopy studies of phospholipid vesicle fusion with a planar phospholipid membrane. Nature of membrane-membrane interactions and detection of release of contents. J. Gen. Physiol., 90, 703-735.

Niles,W.D., Cohen,F.S. and Finkelstein,A. (1989) Hydrostatic pressures developed by osmotically swelling vesicles bound to planar membranes. J. Gen. Physiol., 93, 211-244.

Paulsen,H., Rümler,U. and Rüdiger,W. (1990) Reconstitution of pigment containing complexes from light-harvesting chlorophyll a/b-binding protein overexpressed in Escherichia coli. Planta, 181, 204-211.

Pohlmeyer,K., Soll,J., Steinkamp,T., Hinnah,S. and Wagner,R. (1997) Isolation and characterization of an amino acid-selective channel protein present in the chloroplastic outer envelope membrane. Proc. Natl Acad. Sci. USA, 94, 9504-9509. 


\section{B.Bölter et al.}

Pohlmeyer,K., Soll,J., Grimm,R., Hill,K. and Wagner,R. (1998) A highconductance solute channel in the chloroplastic outer envelope from pea. Plant Cell, 10, 1207-1216.

Rost,B. and Sander,C.J. (1993) Prediction of protein secondary structure at better than 70\% accuracy. Mol. Biol., 232, 584-599.

Rost,B., Casadio,R., Fariselli,P. and Sander,C. (1994) Prediction of transmembrane segments at 95\% accuracy. Protein Sci., 4, 521-533.

Rudel,T., Schmid,A., Benz,R., Kolb,H.A., Lang,F. and Meyer,T.F. (1996) Modulation of Neisseria porin (PorB) by cytosolic ATP/GTP of target cells: parallels between pathogen accommodation and mitochondrial endosymbiosis. Cell, 85, 391-402.

Rutz,J.M., Liu,J., Lyons,J.A., Goranson,J., Armstrong,S.K., McIntosh, M.A., Feix,J.B. and Klebba,P.E. (1992) Formation of a gated channel by a ligand-specific transport protein in the bacterial outer membrane. Science, 258, 471-475.

Samartzidou,H. and Delcour,A.H. (1998) E.coli PhoE porin has an opposite voltage-dependence to the homologous OmpF. EMBO J., 17, 93-100.

Samartzidou,H. and Delcour,A.H. (1999) Excretion of endogenous cadaverine leads to a decrease in porin-mediated outer membrane permeability. J. Bacteriol., 181, 791-798.

Sambrook,J., Fritsch,E.F. and Maniatis,T. (1989) Molecular Cloning: A Laboratory Manual. Cold Spring Harbor Laboratory Press, Cold Spring Harbor, NY.

Sanger,F., Nicklen,S. and Coulson,A.R. (1977) DNA sequencing with chain-terminating inhibitors. Proc. Natl Acad. Sci. USA, 74, $5463-$ 5467.

Schindler,C. and Soll,J. (1986) Protein transport in intact, purified pea etioplasts. Arch. Biochem. Biophys., 247, 211-220.

Schirmer,T., Keller,T.A., Wang,Y.F. and Rosenbusch,J.P. (1995) Structural basis for sugar translocation through maltoporin channels at $3.1 \AA$ resolution. Science, $\mathbf{2 6 7}, 512-514$.

Seedorf,M., Waegemann,K. and Soll,J. (1995) A constituent of the chloroplast import complex represents a new type of GTP-binding protein. Plant J., 7, 401-411.

Smart,O.S., Breed,J., Smith,G.R. and Sansom,M.S. (1997) A novel method for structure-based prediction of ion channel conductance properties. Biophys. J., 72, 1109-1126.

Sreerama,N. and Woody,R.W. (1993) A self-consistent method for the analysis of protein secondary structure from circular dichroism. Anal. Biochem., 209, 32-44.

Sreerama,N. and Woody,R.W. (1994) Poly(pro)II helices in globular proteins: identification and circular dichroic analysis. Biochemistry, 33, 10022-10025.

Stitt,M., Wirtz,W. and Heldt,M. (1980) Metabolite levels during induction in the chloroplast and extrachloroplast compartments of spinach protoplasts. Biochim. Biophys. Acta, 593, 85-102.

Szabo,I., Bathori,G., Wolff,D., Starc,T., Cola,C. and Zoratti,M. (1995) The high-conductance channel of porin-less yeast mitochondria. Biochim. Biophys. Acta, 1235, 115-125.

von Heijne,G. (1992) Membrane protein structure prediction, hydrophobicity analysis and the positive-inside rule. J. Mol. Biol., 225, 487-494.

Waegemann,K. and Soll,J. (1991) Characterization of the protein import apparatus in isolated outer envelopes of chloroplasts. Plant J., $\mathbf{1}$, $149-158$.

Waegemann,K., Eichacker,L. and Soll,J. (1992) Outer envelope membranes of chloroplasts are isolated as right-side-out vesicles. Planta, 187, 89-94.

Walker,K.W. and Bradshaw,R.A. (1999) Yeast methionine aminopeptidase I. Alteration of substrate specificity by site-directed mutagenesis. J. Biol. Chem., 274, 13403-13409.

Zimmerberg,J., Cohen,F.S. and Finkelstein,A. (1980) Fusion of phospholipid vesicles with planar phospholipid bilayer membranes I. Discharge of vesicular contents across the planar membrane. J. Gen. Physiol., 75, 241-250.

Zoratti,M. and Szabo,I. (1995) The mitochondrial permeability transition. Biochim. Biophys. Acta, 1241, 139-176.

Received June 28, 1999; revised August 24, 1999; accepted August 27, 1999 